\title{
Three-Dimensional Elasticity Solutions for Sound Radiation of Functionally Graded Materials Plates considering State Space Method
}

\author{
Tieliang Yang, Qibai Huang, and Shande Li \\ State Key Laboratory of Digital Manufacturing Equipment and Technology, Huazhong University of Science and Technology, \\ Wuhan 430074, China
}

Correspondence should be addressed to Qibai Huang; qbhuang@hust.edu.cn

Received 8 June 2015; Revised 17 August 2015; Accepted 19 August 2015

Academic Editor: Sergio De Rosa

Copyright (C) 2016 Tieliang Yang et al. This is an open access article distributed under the Creative Commons Attribution License, which permits unrestricted use, distribution, and reproduction in any medium, provided the original work is properly cited.

This paper presents an analytical study for sound radiation of functionally graded materials (FGM) plate based on the threedimensional theory of elasticity. The FGM plate is a mixture of metal and ceramic, and its material properties are assumed to have smooth and continuous variation in the thickness direction according to a power-law distribution in terms of volume fractions of the constituents. Based on the three-dimensional theory of elasticity and state space method, the governing equations with variable coefficients of the FGM plate are derived. The sound radiation of the vibration plate is calculated with Rayleigh integral. Comparisons of the present results with those of solutions in the available literature are made and good agreements are achieved. Finally, some parametric studies are carried out to investigate the sound radiation properties of FGM plates.

\section{Introduction}

Functionally graded materials (FGM) are the heterogeneous composite materials with material properties varying smoothly and continuously in one or more directions, and this characteristic properties are usually achieved through continuous change of the volume fraction of the constituent phases [1-3]. The concept of FGM was originally proposed in 1984 by a group of material scientists in Japan as thermal barrier materials, and the superiority to conventional laminated composites of such as eliminating the stress concentration leads to a wider applications of FGM in areas such as aeronautics, astronautics, nuclear, biology, navigation [4]. In practical applications, FGM structures subjected to dynamic load internal or external will generate noise and radiate sound into the surrounding medium, which may result in less comfort. On the other hand, the radiated sound carries useful information of the FGM structures that can be used for nondestructive evaluation or estimation of material properties. Therefore, the investigation of sound radiation of
FGM structures is of great importance from the academic or engineering applications point of view.

Plates are one of the most widely used structural components in industrial applications. Sound radiation from panel structures is a practical engineering problem that has been studied extensively. Numerical methods such as finite element method (FEM) and boundary element method (BEM) [5-7] are always utilized to estimate the sound radiation of structures. However, these methods are computationally expensive, especially at high frequency domain. An infinite extent of plate is always obtained in the research of sound radiation of plate. However, the plate structures are of finite size in practice. Several theories were proposed to take into account the finite size of a plate structure in sound radiation calculation, for example, the spatial windowing technique presented by Villot et al. [8]. As a more general method, the vibration plates are assumed to be placed in an infinite rigid baffle, which, of course, differs from the actual situation in practice, and some authors concentrated on sound radiation from unbaffled plates $[9,10]$. One of the authors 
of this paper studied the sound radiation characteristic from unbaffled rectangular plates [11]. More recently, Putra and Thompson [12,13] also investigated this problem. However, the assumption of an infinite rigid baffle makes the sound radiation problem easier to solve for the fact that the velocity field equals zero everywhere except for the plate surface. In this paper, the assumption of an infinite rigid baffle is also obtained for the convenience in studying the main trends of sound radiation from FGM plate.

Two-dimensional (2D) plate theories such as classic plate theory (CPT), first-order shear deformation theory (FSDT), and higher order shear deformation theories are always utilized in the research of sound radiation of plate-like structures; however, acoustic model based on three-dimensional (3D) elasticity theory may be the sole ultimate choice for more precise calculations. Due to the simplicity, the wellknown classic plate theory [14-16] is utilized conventionally to model the plate in the calculation of sound radiation from plate structures. The CPT is based on the KirchhoffLove hypothesis that straight lines perpendicular to the plane of the undeformed plate remain straight and inextensible and rotate such that they always remain perpendicular to the midplane of the plate after deformation. Nevertheless, neglecting the transverse shear effects and rotary inertia leads to overestimating the natural frequencies of the plate, especially for thick plates or structural response in high frequency range. In order to consider the transverse shear effects on isotropic plates, Reissner [17] and Mindlin [18] developed the FSDT. Hashemi et al. [19] investigated acoustic radiation of rectangular Mindlin plates in different combinations of classical boundary conditions. Cao et al. [20] investigated the sound radiation from infinite stiffened laminated plates theoretically based on the FSDT, and the comparison with Yin's method [21], which is based on CPT, shows that the model based on FSDT and CPT shows a good agreement about the estimation of sound pressure level in the low and medium frequency range, but discrepancies can be found near the coincidence frequency and in the high frequency range. Chandra et al. [22] analytically studied the vibroacoustic response and sound transmission loss characteristics of FGM plates based on a simple FSDT, which was presented by Thai and Choi [23]. As is well-known to all, a shear force correction factor is required in FSDT to take in account the nonuniformity of the shear strain distribution through the thickness. The shear correction factor is typically 5/6 [17] or $\pi^{2} / 12$ [18] for isotropic homogeneous plates; however, the constant shear correction factor is not appropriate for FGM plates due to the material properties and geometric dimension of FGM plates [24, 25]. In order to overcome this shortcoming of FSDT, third-order shear deformation theory (TSDT) or higher order shear deformation theory such as Reddy $[26,27]$ was developed, and no shear correction factors are required and better precision can be achieved. Daneshjou et al. [28] studied sound transmission through relatively thick FGM cylindrical shells based on third-order shear deformation shell theory, and their work denotes that there are some discrepancies between FSDT and TSDT at high frequencies for relatively thick FGM cylindrical shells. However, studies of sound radiation from plate structures

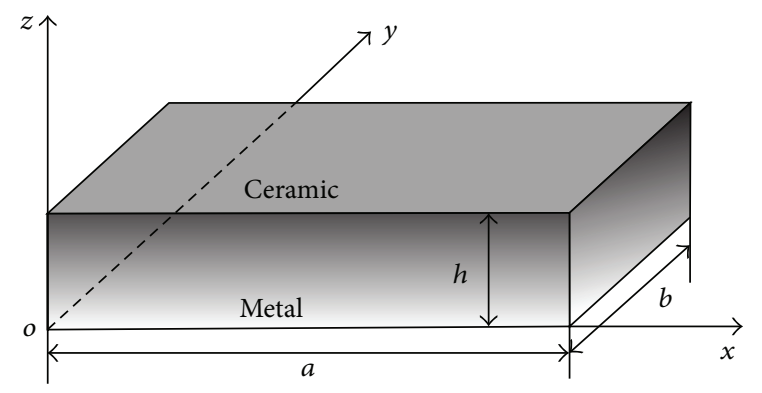

FIGURE 1: Geometry and coordinates of the FGM plate.

based on 3D elasticity may be the sole ultimate choice, which is, however, relatively scarce. Hwang et al. [29] presented an elasticity theory solution for acoustic radiation by a pointor line-excited fluid-loaded laminated plate. Shen et al. [30] studied acoustic radiation from multilayered anisotropic plates based on 3D elasticity model. Hasheminejad and Keshavarzpour [31] studied the active sound radiation control of thick piezolaminated smart plate, and the orthotropic laminated plate is modeled based on 3D piezoelasticity theory with the use of state space formulation. Huang and Nutt [32] developed a unique analytical formulation for sound transmission of unbounded FGM panels by employing threedimensional theory of elasticity and state space method.

In the present paper, the sound radiation of FGM plates with arbitrary thickness is investigated. An analytical model of sound radiation of FGM plates based on the threedimensional theory of elasticity is proposed. By means of state space formulation and modal expansion, the threedimensional governing equations of elastodynamics are converted into a set of ordinary differential equations with variable coefficients for FGM plate. The solution of the ordinary differential equations results in the transfer matrix relating the top and bottom surface of the plate. Some similar procedures were also used in prior plates studies such as vibration [33-35], wave propagation [36-38], and sound transmission [32]. The external loads including point load, line load, and distributed load are expanded into a double Fourier series form and applied on the surface. Applying the continuity of displacement and stresses at the interfaces of plate leads to global governing equations of the vibroacoustic system, and then sound radiation of the plate is calculated using Rayleigh integral with a primitive numerical scheme.

\section{Theoretical Formulation}

Consider a rectangular FGM plate with length $a$, width $b$, and an arbitrarily constant thickness $h$, as shown in Figure 1. A Cartesian coordinate system $(x, y, z)$ is located at the corner of the panel on the bottom surface of the plate. The plate is assumed to be placed in an infinite rigid baffler. The FGM plate is under the excitation of external load on the surface and the fluid structure interaction between the plate and the surrounding air is not considered. 
2.1. Material Properties. The FGM plate is assumed to be made from a mixture of two material phases, for example, a metal and a ceramic, as shown in Figure 1. The materials at the top surface $(z=h)$ and the bottom surface $(z=0)$ of the FGM panel are purely ceramic and metal, respectively. Within the top surface and bottom surface, the volume fraction of each constituent material changes smoothly through the thickness from one surface to the other, and all constituent materials are assumed in their elastic range. The material property $P(z)$ of the panel such as density $\rho$, Young's modulus $E$, and Poisson's ratio $\nu$ can be expressed as a function of the material properties and volume fractions of constituents [26]

$$
P(z)=P_{c} V_{c}+P_{m} V_{m}
$$

where the subscripts $c$ and $m$ represent the ceramic and metallic constituents, respectively. $\left(P_{c}, V_{c}\right)$ and $\left(P_{m}, V_{m}\right)$ denote material properties and volume fraction of ceramic and metal, respectively. The volume fraction of the constituent material is assumed as [26]

$$
\begin{aligned}
V_{c} & =\left(\frac{z}{h}\right)^{N}, \\
V_{c}+V_{m} & =1,
\end{aligned}
$$

$(0 \leq z \leq h)$

where $h$ is the thickness of the panel, $z$ is the thickness coordinate, and $N$ denotes the power-law index that takes values greater than or equal to zero. Substituting (2) into (1) yields

$$
P(z)=P_{m}+\left(P_{c}-P_{m}\right)\left(\frac{z}{h}\right)^{N}
$$

and according to (3), density $\rho$, Young's modulus $E$, and Poisson's ratio $\nu$ can be written as

$$
\begin{aligned}
& \rho(z)=\rho_{m}+\left(\rho_{c}-\rho_{m}\right)\left(\frac{z}{h}\right)^{N}, \\
& E(z)=E_{m}+\left(E_{c}-E_{m}\right)\left(\frac{z}{h}\right)^{N}, \\
& \nu(z)=v_{m}+\left(\nu_{c}-v_{m}\right)\left(\frac{z}{h}\right)^{N} .
\end{aligned}
$$

2.2. Structural Model. In the absence of body forces, the equations of motion are

$$
\begin{aligned}
& \frac{\partial \sigma_{x x}}{\partial x}+\frac{\partial \tau_{y x}}{\partial y}+\frac{\partial \tau_{z x}}{\partial z}=\rho \frac{\partial^{2} u}{\partial^{2} t} \\
& \frac{\partial \tau_{x y}}{\partial x}+\frac{\partial \sigma_{y y}}{\partial y}+\frac{\partial \tau_{z y}}{\partial z}=\rho \frac{\partial^{2} v}{\partial^{2} t} \\
& \frac{\partial \tau_{x z}}{\partial x}+\frac{\partial \tau_{y z}}{\partial y}+\frac{\partial \sigma_{z z}}{\partial z}=\rho \frac{\partial^{2} w}{\partial^{2} t}
\end{aligned}
$$

where $\rho$ is the density of the plate and $\mathbf{u}=(u, v, w)^{\mathrm{T}}$ and $\boldsymbol{\sigma}=\left(\sigma_{x x}, \sigma_{y y}, \sigma_{z z}, \tau_{y z}, \tau_{x z}, \tau_{x y}\right)^{\mathrm{T}}$ are the column vectors of the displacement and stresses, respectively.

The linear relations between the strain and the displacement are

$$
\begin{aligned}
& \varepsilon_{x x}=\frac{\partial u}{\partial x}, \\
& \varepsilon_{y y}=\frac{\partial v}{\partial y}, \\
& \varepsilon_{z z}=\frac{\partial w}{\partial z}, \\
& \gamma_{z y}=\frac{\partial w}{\partial y}+\frac{\partial v}{\partial z}, \\
& \gamma_{z x}=\frac{\partial w}{\partial x}+\frac{\partial u}{\partial z}, \\
& \gamma_{x y}=\frac{\partial v}{\partial x}+\frac{\partial u}{\partial y},
\end{aligned}
$$

where $\boldsymbol{\varepsilon}=\left(\varepsilon_{x x}, \varepsilon_{y y}, \varepsilon_{z z}, \gamma_{y z}, \gamma_{x z}, \gamma_{x y}\right)^{\mathrm{T}}$ is the strain components.

The constitutive relations can be expressed in general Hooke's law

$$
\sigma=\mathrm{C} \boldsymbol{c}
$$

where $\mathbf{C}$ is the stiffness matrix as follows:

$$
\mathbf{C}=\left(\begin{array}{cccccc}
c_{11} & c_{12} & c_{13} & 0 & 0 & 0 \\
c_{21} & c_{22} & c_{33} & 0 & 0 & 0 \\
c_{31} & c_{32} & c_{33} & 0 & 0 & 0 \\
0 & 0 & 0 & c_{44} & 0 & 0 \\
0 & 0 & 0 & 0 & c_{55} & 0 \\
0 & 0 & 0 & 0 & 0 & c_{66}
\end{array}\right)
$$

where $c_{i j}$ is the stiffness coefficients. For the sake of generality, they are the function of $z$; that is, $c_{i j}=c_{i j}(z)$.

Following the state space method [33, 34], we select $u, v, w, \sigma_{z z}, \tau_{y z}$, and $\tau_{x z}$ as state variables. After combining 
(5)-(7), the thickness first derivatives of the state variables can be written as

$$
\begin{aligned}
\frac{\partial u}{\partial z}= & \frac{\tau_{z x}}{c_{55}}-\frac{\partial w}{\partial x}, \\
\frac{\partial v}{\partial z}= & \frac{\tau_{z y}}{c_{44}}-\frac{\partial w}{\partial y}, \\
\frac{\partial w}{\partial z}= & \frac{\sigma_{z z}}{c_{33}}-\frac{c_{31}}{c_{33}} \frac{\partial u}{\partial x}-\frac{c_{32}}{c_{33}} \frac{\partial v}{\partial y}, \\
\frac{\partial \tau_{z y}}{\partial z}= & \rho \frac{\partial^{2} v}{\partial t^{2}}-\left(c_{66}+c_{21}-\frac{c_{23} c_{31}}{c_{33}}\right) \frac{\partial^{2} u}{\partial x \partial y}-\frac{c_{32}}{c_{33}} \frac{\partial \sigma_{z z}}{\partial y} \\
& -\left(c_{66} \frac{\partial^{2}}{\partial x^{2}}+c_{22} \frac{\partial^{2}}{\partial y^{2}}-\frac{c_{23}}{c_{33}} \frac{\partial^{2}}{\partial y^{2}}\right) v,
\end{aligned}
$$$$
\begin{aligned}
\mathbf{A}_{11} & =\left[\begin{array}{ccc}
0 & 0 & -\frac{\partial}{\partial x} \\
0 & 0 & -\frac{\partial}{\partial y} \\
-\frac{c_{31}}{c_{33}} \frac{\partial}{\partial x} & -\frac{c_{32}}{c_{33}} \frac{\partial}{\partial y} & 0
\end{array}\right], \\
\mathbf{A}_{12} & =\left[\begin{array}{ccc}
0 & \frac{1}{c_{55}} & 0 \\
\frac{1}{c_{44}} & 0 & 0 \\
0 & 0 & \frac{1}{c_{33}}
\end{array}\right]
\end{aligned}
$$$$
\mathbf{A}_{22}=\left[\begin{array}{ccc}
0 & 0 & -\frac{c_{32}}{c_{33}} \frac{\partial}{\partial y} \\
0 & 0 & -\frac{c_{13}}{c_{33}} \frac{\partial}{\partial x} \\
-\frac{\partial}{\partial y} & -\frac{\partial}{\partial x} & 0
\end{array}\right],
$$$$
\mathbf{A}_{21}=\left[\begin{array}{ccc}
-\left(c_{66}+c_{21}-\frac{c_{23} c_{31}}{c_{33}}\right) \frac{\partial^{2}}{\partial x \partial y} & \rho \frac{\partial^{2}}{\partial t^{2}}-\left(c_{66} \frac{\partial^{2}}{\partial x^{2}}+c_{22} \frac{\partial^{2}}{\partial y^{2}}-\frac{c_{23}^{2}}{c_{33}} \frac{\partial^{2}}{\partial y^{2}}\right) & 0 \\
\rho \frac{\partial^{2}}{\partial t^{2}}-\left(c_{11}-\frac{c_{13} c_{31}}{c_{33}}\right) \frac{\partial^{2}}{\partial x^{2}}-c_{66} \frac{\partial^{2}}{\partial y^{2}} & -\left(c_{66}+c_{12}-\frac{c_{13} c_{32}}{c_{33}}\right) \frac{\partial^{2}}{\partial x \partial y} & 0 \\
0 & 0 & \rho \frac{\partial^{2}}{\partial t^{2}}
\end{array}\right] .
$$

$$
\frac{\partial}{\partial z}\left\{\begin{array}{c}
\mathbf{u} \\
\sigma_{1}
\end{array}\right\}=\left[\begin{array}{ll}
\mathbf{A}_{11} & \mathbf{A}_{12} \\
\mathbf{A}_{21} & \mathbf{A}_{22}
\end{array}\right]\left\{\begin{array}{c}
\mathbf{u} \\
\sigma_{1}
\end{array}\right\},
$$

where $\sigma_{1}=\left(\tau_{y z}, \tau_{x z}, \sigma_{z z}\right)^{\mathrm{T}}$ and

Equation (9) can be rewritten into a compact form as

For a rectangular plate simply supported and grounded on all four sides, the boundary conditions on the edges are [34]

$$
\begin{aligned}
& \sigma_{x x}=v=w=0, \quad \text { at } x=0, a, \\
& \sigma_{y y}=u=w=0, \quad \text { at } y=0, b .
\end{aligned}
$$


To satisfy the simply supported boundary conditions (12), the state variables are assumed as the following form [33-35]:

$$
\left\{\begin{array}{c}
\mathbf{u} \\
\boldsymbol{\sigma}_{1}
\end{array}\right\}=\sum_{m=1}^{\infty} \sum_{n=1}^{\infty}\left\{\begin{array}{c}
\bar{u}(z) \cos \left(\frac{m \pi x}{a}\right) \sin \left(\frac{n \pi y}{b}\right) \\
\bar{v}(z) \sin \left(\frac{m \pi x}{a}\right) \cos \left(\frac{n \pi y}{b}\right) \\
\bar{w}(z) \sin \left(\frac{m \pi x}{a}\right) \sin \left(\frac{n \pi y}{b}\right) \\
\bar{\tau}_{y z}(z) \sin \left(\frac{m \pi x}{a}\right) \cos \left(\frac{n \pi y}{b}\right) \\
\bar{\tau}_{x z}(z) \cos \left(\frac{m \pi x}{a}\right) \sin \left(\frac{n \pi y}{b}\right) \\
\bar{\sigma}_{z z}(z) \sin \left(\frac{m \pi x}{a}\right) \sin \left(\frac{n \pi y}{b}\right)
\end{array}\right\}
$$

$\cdot \exp (i \omega t)$,

$$
\begin{aligned}
\mathbf{K} & =\left[\begin{array}{ll}
\mathbf{K}_{11} & \mathbf{K}_{12} \\
\mathbf{K}_{21} & \mathbf{K}_{22}
\end{array}\right], \\
\mathbf{K}_{11} & =\left[\begin{array}{ccc}
0 & 0 & -\frac{m \pi}{a} \\
0 & 0 & -\frac{n \pi}{b} \\
\frac{c_{31} m \pi}{\left(c_{33} a\right)} & \frac{c_{32} n \pi}{\left(c_{33} b\right)} & 0
\end{array}\right], \\
\mathbf{K}_{12} & =\left[\begin{array}{ccc}
0 & \frac{1}{c_{55}} & 0 \\
\frac{1}{c_{44}} & 0 & 0 \\
0 & 0 & \frac{1}{c_{33}}
\end{array}\right], \\
\mathbf{K}_{22} & =\left[\begin{array}{ccc}
0 & 0 & -\frac{c_{23} n \pi}{\left(c_{33} b\right)} \\
0 & 0 & -\frac{c_{13} m \pi}{\left(c_{33} a\right)} \\
\frac{n \pi}{b} & \frac{m \pi}{a} & 0
\end{array}\right], \\
\mathbf{K}_{21} & =\left[\begin{array}{cc}
\frac{\left(c_{66}+c_{21}-c_{23} c_{31} / c_{33}\right) m n \pi^{2}}{(a b)} \\
-\rho \omega^{2}+c_{66}\left(\frac{n \pi}{b}\right)^{2}+\left(c_{11}-\frac{c_{13} c_{31}}{c_{33}}\right)\left(\frac{m \pi}{a}\right)^{2} \\
0
\end{array}\right.
\end{aligned}
$$

As $c_{i j}$ is a function of the $z$-coordinate, the system matrix $\mathbf{K}$ is nonconstant but $z$-dependant. Then the problem reduces to find the solution of an ordinary differential equation system with nonconstant coefficients. The analytical solution of (14) can be expressed as the following form:

$$
\bar{\psi}\left(z_{1}\right)=\mathbf{M}\left(z_{1}, z_{0}\right) \bar{\psi}\left(z_{0}\right),
$$

where $\mathbf{M}\left(z_{1}, z_{0}\right)$ is the matricant, which relates the value of the state vector at $z=z_{1}$, that is, $\bar{\psi}\left(z_{1}\right)$, to the value of the state where $i=\sqrt{-1}, \omega$ is the circular frequency, and $\bar{u}(z), \bar{v}(z)$, $\bar{w}(z), \bar{\tau}_{y z}(z), \bar{\tau}_{x z}(z)$, and $\bar{\sigma}_{z z}(z)$ are undetermined coefficients. Substitution of (13) into (10) using the orthogonal property of the sinusoidal function in (13) and (10) yields

$$
\frac{d \bar{\psi}(z)}{d z}=\mathbf{K} \bar{\psi}(z)
$$

where $\bar{\psi}(\mathbf{z})=\left[\overline{\mathbf{u}}, \overline{\boldsymbol{\sigma}}_{1}\right]^{\mathrm{T}}=\left[\bar{u}(z), \bar{v}(z), \bar{w}(z), \bar{\tau}_{y z}(z), \bar{\tau}_{x z}(z)\right.$, $\left.\bar{\sigma}_{z z}(z)\right]^{\mathrm{T}}$ and matrix $\mathbf{K}$ is vector at $z=z_{0}$, that is, $\bar{\psi}\left(z_{0}\right)$. The matricant for $\mathbf{M}\left(z_{1}, z_{0}\right)$ can be defined explicitly by the so-called multiplicative integral satisfying the Peano series expansion [36-38]

$$
\begin{aligned}
\mathbf{M}\left(z_{1}, z_{0}\right)= & \mathbf{I}+\int_{z_{0}}^{z_{1}} \mathbf{K}(\tau) d \tau \\
& +\int_{z_{0}}^{z_{1}} \mathbf{K}(\tau) \int_{z_{0}}^{\tau} \mathbf{K}\left(\tau_{1}\right) d \tau_{1} d \tau+\cdots,
\end{aligned}
$$


where $\mathbf{I}$ is the identity matrix of dimension $6 \times 6$. If the matrix $\mathbf{K}(z)$ is bounded in the study interval, these series are always convergent $[37,40]$. This solution to (14) is exact and unique. In addition, a piecewise constant method can be obtained as an alternative [41-43]; that is, divide the plate equally into numbers of sublayers, and the material parameters of each layer are assumed constant. It is clear that an adequate number of layers in the piecewise constant method can ensure the accuracy of the solution. In the piecewise constant method, the matricant relating the value of the state vector $\bar{\psi}\left(z_{1}\right)$ to the value of the state vector $\bar{\psi}\left(z_{0}\right)$ can be expressed as

$$
\mathbf{M}\left(z_{1}, z_{0}\right)=\prod_{j=p}^{j=1} \exp ^{\left(\left(z_{1}-z_{0}\right) / p\right) \mathbf{K}(j)},
$$

where $p$ is the number of sublayers and $\mathbf{K}(j)$ is the system matrix of each sublayer and takes the value at each midsurface. In addition, the matrix exponential $\exp \left(\left(\left(z_{1}-\right.\right.\right.$ $\left.\left.\left.z_{0}\right) / p\right) \mathbf{K}(j)\right)$ in (18) can be directly calculated by using builtin function in Mathematica or Matlab to avoid complex algebraic manipulations [32, 35].

Using the matricant obtained, the relationship between the state vectors $\bar{\psi}(h)$ and $\bar{\psi}(0)$ can be established as

$$
\bar{\psi}(h)=\mathbf{M}(h, 0) \bar{\psi}(0)
$$

and the equation can be expressed in detail as

$$
\left(\begin{array}{c}
\overline{\mathbf{u}}(h) \\
\overline{\boldsymbol{\sigma}}_{1}(h)
\end{array}\right)=\left[\begin{array}{ll}
\mathbf{M}_{11} & \mathbf{M}_{12} \\
\mathbf{M}_{21} & \mathbf{M}_{22}
\end{array}\right]\left(\begin{array}{c}
\overline{\mathbf{u}}(0) \\
\overline{\boldsymbol{\sigma}}_{1}(0)
\end{array}\right),
$$

where $\mathbf{M}_{i j}$ are entries of the matrix $\mathbf{M}(h, 0)$.

2.3. Transverse Load. In this paper, only the transverse load on the surface of the plate is considered and the load $q(x, y)$ is assumed to be expanded into a double Fourier series form as [44]

$$
q(x, y)=\sum_{m=1}^{\infty} \sum_{n=1}^{\infty} q_{m n} \sin \left(\frac{m \pi x}{a}\right) \sin \left(\frac{n \pi y}{b}\right),
$$

where $q_{m n}$ is the load coefficient and for a load $q(x, y)$ the load coefficient $q_{m n}$ is given as

$$
\begin{aligned}
& q_{m n} \\
& \quad=\frac{4}{a b} \int_{0}^{a} \int_{0}^{b} q(x, y) \sin \left(\frac{m \pi x}{a}\right) \sin \left(\frac{n \pi x}{b}\right) d x d y .
\end{aligned}
$$

For a concentrated load $q(x, y)=q_{0} \delta\left(x-x_{0}\right) \delta\left(y-y_{0}\right)$, where $\delta\left(x-x_{0}\right)$ and $\delta\left(y-y_{0}\right)$ are Delta-functions such that at $x=x_{0}, y=y_{0}$, they are of value one and vanish elsewhere, as shown in Figure 2. The load coefficient for a concentrated load can be expanded as follows according to (21) and (22):

$$
q_{m n}=\frac{4 q_{0}}{a b} \sin \left(\frac{m \pi x_{0}}{a}\right) \sin \left(\frac{n \pi y_{0}}{b}\right),
$$

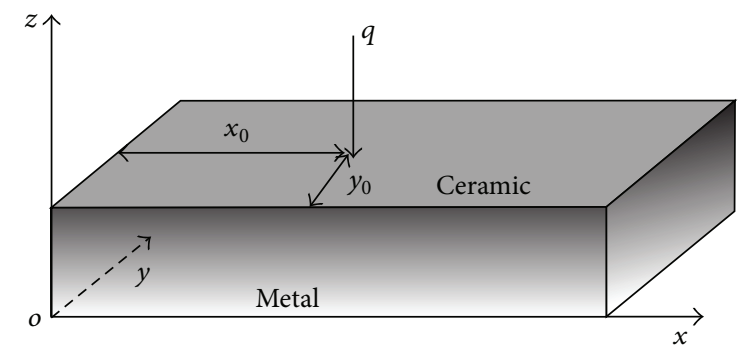

Figure 2: FGM plate subjected to point load.

For a line load $q(x, y)=q_{0} \delta\left(x-x_{0}\right)$, which is shown in Figure 3(a), the load coefficient can be expanded as follows according to (21) and (22):

$$
\begin{aligned}
q_{m n}=\frac{8 q_{0}}{n \pi a} \sin \left(\frac{m \pi x_{0}}{a}\right), & \\
m & =1,2,3 \cdots, n=1,3,5 \cdots .
\end{aligned}
$$

For a line load $q(x, y)=q_{0} \delta\left(y-y_{0}\right)$, which is shown in Figure 3(b), the load coefficient can be expanded as follows according to (21) and (22):

$$
\begin{aligned}
q_{m n}=\frac{8 q_{0}}{m \pi b} \sin \left(\frac{n \pi y_{0}}{b}\right), & \\
n & =1,2,3 \cdots, m=1,3,5 \cdots .
\end{aligned}
$$

For uniformly distributed load $q(x, y)=q_{0}$, which is shown in Figure 4, the load coefficient can be expanded as follows according to (21) and (22):

$$
q_{m n}=\frac{16 q_{0}}{m n \pi^{2}}, \quad m, n=1,3,5 \cdots .
$$

2.4. Structural Dynamic Response of FGM Plate. The surface boundary conditions of FGM plate subjected transverse force on the top surface are

$$
\begin{aligned}
& \tau_{z x}(h)=\tau_{z y}(h)=\sigma_{z z}(0)=\tau_{z x}(0)=\tau_{z y}(0)=0, \\
& \sigma_{z z}(h)=q .
\end{aligned}
$$

Equation (27) can be regrouped into the matrix form as

$$
\begin{aligned}
& \sigma_{1}(h)=(0,0, q)^{\mathrm{T}}, \\
& \sigma_{1}(0)=(0,0,0)^{\mathrm{T}} .
\end{aligned}
$$

Combining the relationship between $\sigma_{1}$ and $\bar{\sigma}_{1}$, the following equation can be obtained:

$$
\begin{aligned}
& \overline{\boldsymbol{\sigma}}_{1}(h)=\left(0,0, q_{m n}\right)^{\mathrm{T}}, \\
& \overline{\boldsymbol{\sigma}}_{1}(0)=(0,0,0)^{\mathrm{T}} .
\end{aligned}
$$

Substituting (29) into (20), the forced response of displacement in top surface of the plate subjected transverse force on the top surface can be obtained:

$$
\overline{\mathbf{u}}(h)=\mathbf{M}_{11} \mathbf{M}_{21}^{-1} \overline{\boldsymbol{\sigma}}(h) .
$$




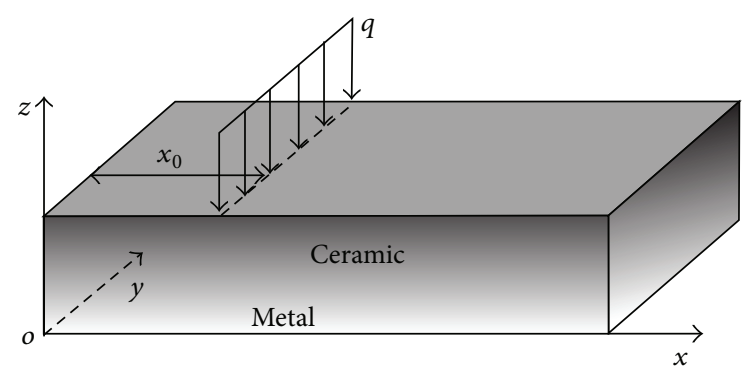

(a)

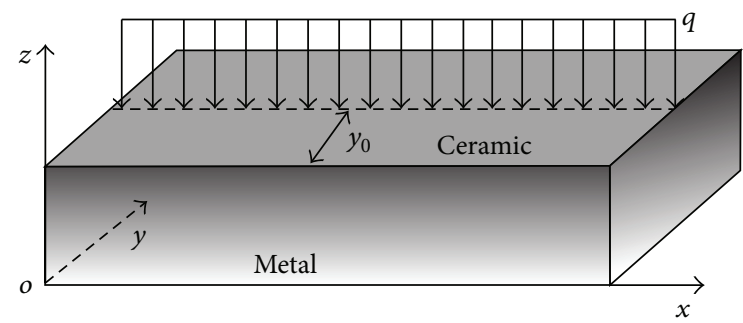

(b)

FIGURE 3: FGM plate subjected to line load: (a) the line load $q(x, y)=q_{0} \delta\left(x-x_{0}\right)$ and (b) the line load $q(x, y)=q_{0} \delta\left(y-y_{0}\right)$.

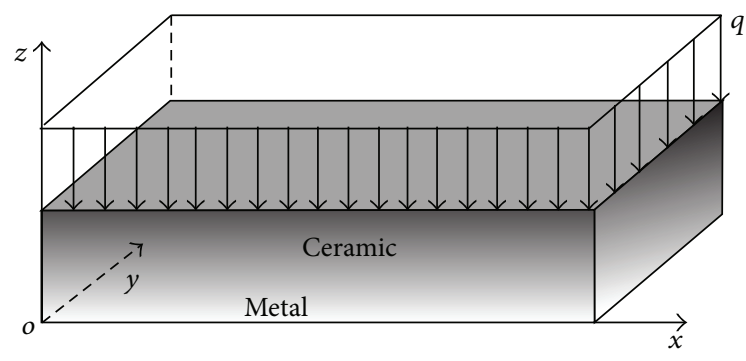

Figure 4: FGM plate subjected to distributed load.

In a similar method, the forced response of displacement on the top surface of the plate subjected transverse force on the bottom surface can be given as

$$
\overline{\mathbf{u}}(h)=\left(-\mathbf{M}_{11} \mathbf{M}_{21}^{-1} \mathbf{M}_{22}+\mathbf{M}_{12}\right) \overline{\boldsymbol{\sigma}}(0),
$$

where $\overline{\boldsymbol{\sigma}}(0)=\left(0,0, q_{m n}\right)^{\mathrm{T}}$.

For free vibration, the surface boundary conditions are

$$
\begin{aligned}
\tau_{z x}(h) & =\tau_{z y}(h)=\sigma_{z z}(0)=\tau_{z x}(0)=\tau_{z y}(0) \\
& =\sigma_{z z}(h)=0 .
\end{aligned}
$$

Equation (32) can be regrouped into matrix as

$$
\boldsymbol{\sigma}_{1}(h)=\boldsymbol{\sigma}_{1}(0)=(0,0,0)^{\mathrm{T}} .
$$

Combining (20), a system equation can be obtained

$$
\mathbf{0}=\mathbf{M}_{21} \overline{\mathbf{u}}(0) .
$$

The natural frequency has an important effect on the sound radiation, and the natural frequency can be obtained by solving the equation $\operatorname{det}\left(\mathbf{M}_{21}\right)=0$.

2.5. Sound Radiation Power. When subjected to external excitation, the FGM plate will be stimulated and will radiate noise into the surrounding acoustic medium. It is convenient to characterize the sound radiated from a vibrating structure by a single global quantity such as sound radiation power. There are two different approaches generally used to determine the sound power. The first is to integrate the acoustic intensity over the vibrating surface, and the second is to integrate the squared pressure on a hemisphere in the far field [15]. Only the first one is adopted in this work. The radiated sound power can be obtained by integrating the acoustic intensity over the surface of the plate [39]:

$$
\bar{W}=\int_{S} 0.5 \operatorname{Re}\left(\dot{w}^{*}\left(\mathbf{r}_{s}\right) p(\mathbf{r})\right) d S,
$$

where $\mathrm{Re}$ and superscript $*$ denote the real part and the complex conjugate, respectively, $S$ is the surface of the plate, $\dot{w}\left(\mathbf{r}_{s}\right)$ is the normal velocity of the surface point $\mathbf{r}_{s}$, and $p(\mathbf{r})$ is the complex pressure amplitude at location $\mathbf{r}$. For a plate placed in an infinite baffled surface, the acoustic pressure at any field point $\mathbf{r}$ can be expressed in terms of surface complex velocity $\dot{w}\left(\mathbf{r}_{s}\right)$ according to Rayleigh integral [45]:

$$
p(\mathbf{r})=\frac{j \omega \rho_{0}}{2 \pi} \int_{S} \dot{w}\left(\mathbf{r}_{s}\right) \frac{\exp \left(-j k r^{\prime}\right)}{r^{\prime}} d S,
$$

where $r^{\prime}=\left|\mathbf{r}-\mathbf{r}_{s}\right|$ is the distance between a surface point $\mathbf{r}_{s}$ and a field point $\mathbf{r}, k$ is the acoustic wavenumber and $k=\omega / c_{0}$ with $c_{0}$ being the speed of sound in the medium, and $\rho_{0}$ is the density of the medium.

In this paper, a primitive numerical scheme is used to solve the Rayleigh integral as $[22,46]$. The plate is divided into $M \times N$ equal size rectangular elements, and the normal velocity is assumed to be constant across the rectangular elements. This approximation is sufficiently accurate if the characteristic length of the elemental radiator $\sqrt{S_{e l}}$ is much smaller than half of the minimum acoustic wavelength. Then the sound pressure in (36) can be written as

$$
p(\mathbf{r})=\mathbf{Z} \dot{\mathbf{w}}_{n}\left(r_{s}\right),
$$

where $\dot{\mathbf{w}}_{n}\left(r_{s}\right)$ is the vector with normal surface velocities of the elemental radiators and $\mathbf{Z}$ is the radiation impedance matrix given by

$$
Z_{i j}=\frac{j \omega \rho_{0} S_{e l}}{2 \pi} \frac{\exp \left(-j k r_{i j}\right)}{r_{i j}} .
$$

It is noted that the singular diagonal elements of the impedance matrix $Z$ are singular when the field point is on the vibration plate surface (then $i=j, r_{i j}=0$ ), and some approximations can be used as $[22,47]$

$$
Z_{i i}=\rho_{0} c_{0}\left(1-\exp \left(-j k \sqrt{\frac{S_{e l}}{\pi}}\right)\right) .
$$


The radiated sound power in (35) can be formulated as [22]

$$
\bar{W}=\dot{\mathbf{w}}_{n}^{H}(\mathbf{r}) \mathbf{R} \dot{\mathbf{w}}(\mathbf{r}),
$$

where $\mathbf{R}$ is the radiation resistance matrix, and for plate radiators placed in an infinite baffle the radiation resistance matrix can be written as

$$
\begin{aligned}
R= & \frac{\rho_{0} \omega^{2} S_{e l}^{2}}{4 \pi c_{0}} \\
& {\left[\begin{array}{cccc}
\frac{\sin \left(k r_{12}\right)}{\left(k r_{12}\right)} & \cdots & \frac{\sin \left(k r_{1 n}\right)}{\left(k r_{1 n}\right)} \\
\frac{\sin \left(k r_{21}\right)}{\left(k r_{21}\right)} & 1 & \cdots & \frac{\sin \left(k r_{2 n}\right)}{\left(k r_{2 n}\right)} \\
\vdots & \vdots & \ddots & \vdots \\
\frac{\sin \left(k r_{n 1}\right)}{\left(k r_{n 1}\right)} & \frac{\sin \left(k r_{n 2}\right)}{\left(k r_{n 2}\right)} & \cdots & 1
\end{array}\right] . }
\end{aligned}
$$

The radiated sound power is usually written in the form of sound power level in decibel, which is defined by

$$
\mathrm{SPL}=10 \log \left(\frac{\bar{W}}{\overline{\bar{W}}_{0}}\right)
$$

where $\bar{W}_{0}$ is the reference power and $\bar{W}_{0}=1 \times 10^{-12} \mathrm{~W}$.

\section{Numerical Results and Discussions}

3.1. Validation Examples. In order to prove the validity of the present formulation and the developed code, the obtained results for sound radiation from the homogeneous plates as well as FGM plates have been compared with those available in the literature.

The first example is sound radiation of a simply supported isotropic rectangular plate made of steel, which was analyzed by S. Li and X. H. Li [39] and Jeyaraj et al. [5]. The plate is assumed to vibrate in air and with dimensions of $0.455 \mathrm{~m} \times$ $0.379 \mathrm{~m} \times 0.003 \mathrm{~m}$. Figure 5 shows the comparisons of the present study with those of S. Li and X. H. Li [39] and Jeyaraj et al. [5]. The finite element method based on Mindlin plate theory was used to model the plate and sound power level was calculated using the Rayleigh integral in S. Li and X. H. $\mathrm{Li}$ [39]. The finite element method based on classical laminate plate theory was used to obtain the vibration response of the plate and the sound power level of the plate was calculated using SYSNOISE in Jeyaraj et al. [5]. In the present work, the structural dynamic response of the plate is obtained by state space method based on 3D elasticity, and the Rayleigh integral is also used in calculation of sound radiation power. As is illustrated in Figure 5, an excellent agreement of the predictions of sound power level has been achieved between the present work and the work of S. Li and X. H. Li [39] and a relatively larger prediction of the sound power level is found in Jeyaraj et al. [5]. This is due to the fact that the sound power level was obtained by adopting the Rayleigh integral in present work as well as in S. Li and X. H. Li [39], while that

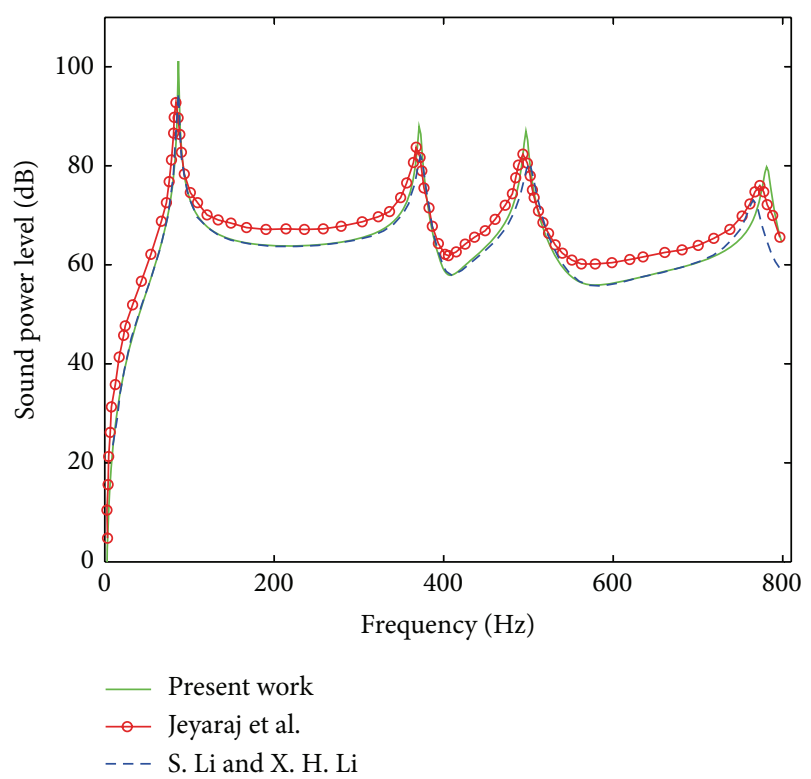

FIgURE 5: Comparisons of sound power level of an isotropic plate with Jeyaraj et al. [5] and S. Li and X. H. Li [39].

was calculated using SYSNOISE in Jeyaraj et al. [5]. The peaks of sound power level correspond to the natural frequencies of the plate. As depicted in the figure, an excellent agreement has been achieved among the three predictions of the first three peaks; however, there are some considerable discrepancies at high frequencies, that is, around $800 \mathrm{~Hz}$. This is due to the fact that 2D plate theories were used in Jeyaraj et al. [5] and S. Li and X. H. Li [39], while the present model is based on 3D elasticity, which can give the exact solution for this system at high frequency. In conclusion, these comparisons validate the present model.

The second validation example is sound radiation from FGM plates $\left(\mathrm{Al} / \mathrm{Al}_{2} \mathrm{O}_{3}\right)$ under the excitation of point force which is taken from Chandra et al. [22]. The plate is assumed to be simply supported on all edges and with the dimensions of $0.5 \mathrm{~m} \times 0.4 \mathrm{~m} \times 0.003 \mathrm{~m}$. FGM plates with three distinct power-law indexes, that is, the power-law indexes $N=0, N=$ 1 , and $N=5$, are considered. Figure 6 shows the comparison of the prediction of the present work and Chandra et al. [22], while the structural modes corresponding to peaks are listed in Table 1 and the difference between the two predictions of the structural modes is smaller than $1 \mathrm{~Hz}$. The FSDT was adopted in Chandra et al. [22], and the present work is based on the three-dimensional theory of elasticity. It can be found that the two methods match well for the prediction of sound power level and the frequencies where peaks occur over a wide frequency range. It is noted that a peak is lost in the result of Chandra et al. [22] for $N=5$. This is for the reason that only the first 25 structural modes were considered in Chandra et al. [22] to calculate the structural response of the FGM plate, and the structural mode $(m, n)=(7,1)$ corresponding to the lost peak, which is the 27th mode with the frequency of $1890 \mathrm{~Hz}$ as shown in Table 1, was not considered. 


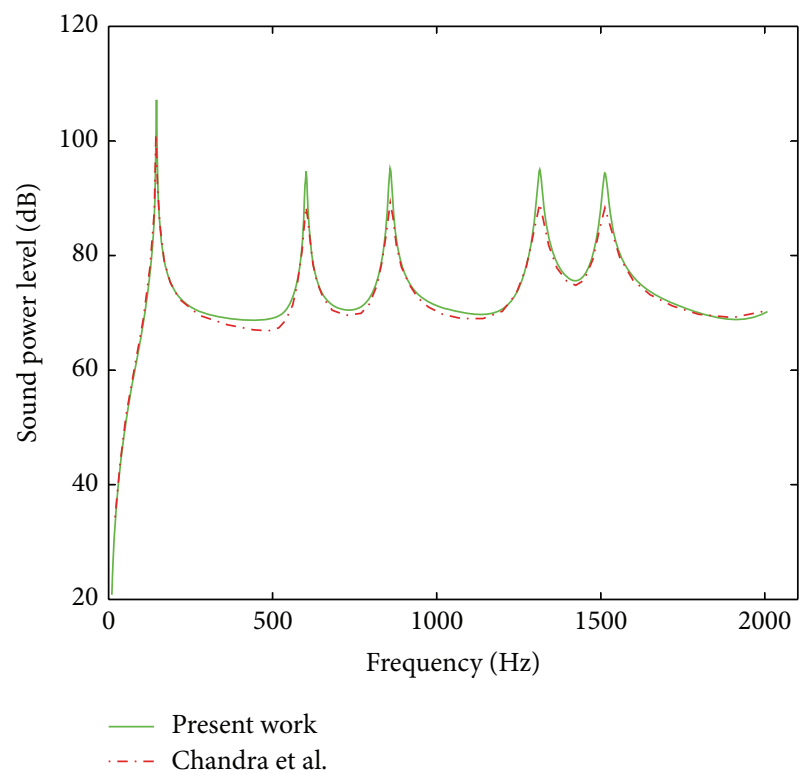

(a)

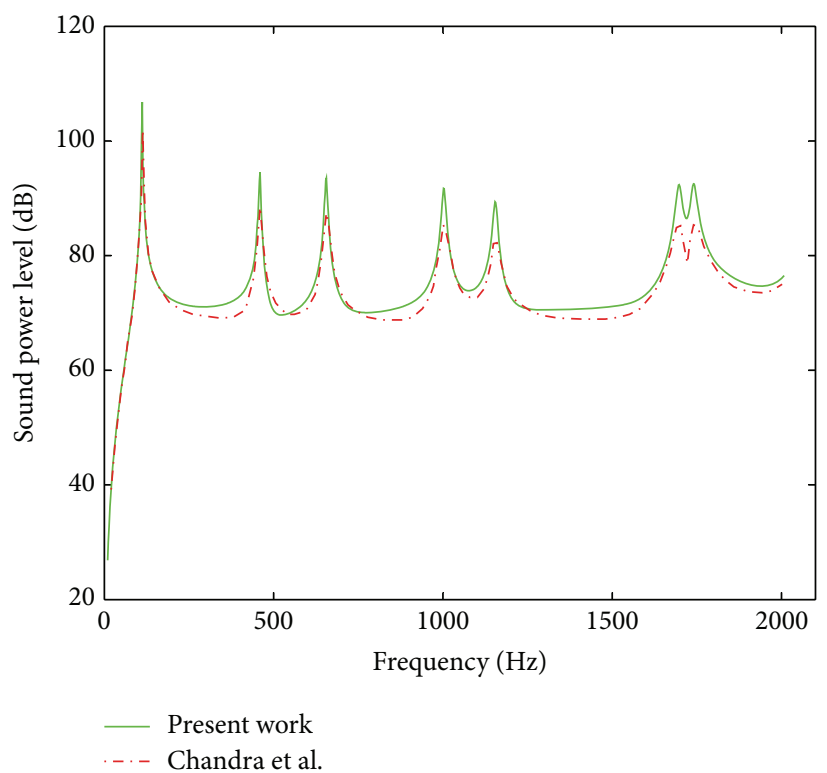

(b)

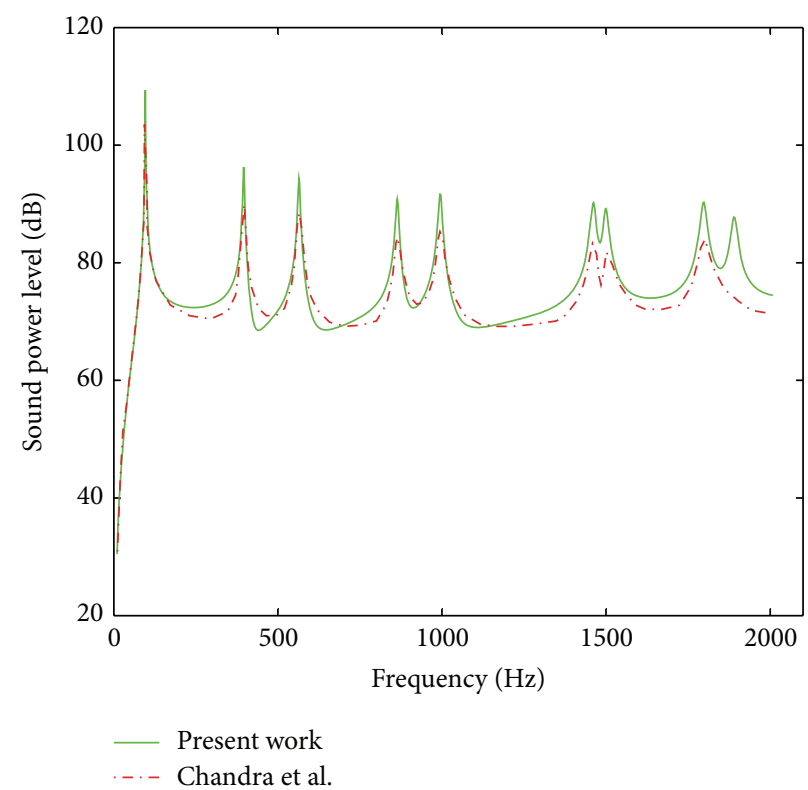

(c)

FIGURE 6: Comparisons of sound power level of FGM plate with Chandra et al. [22]: (a) power-law index $N=0$, (b) power-law index $N=1$, and (c) power-law index $N=5$.

There are some discrepancies in the prediction of the sound radiation power of FGM plates. As is shown in Figure 6, an excellent agreement has been achieved between the two methods for FGM plate with power-law index $N=0$, and some discrepancies occur at high frequencies when the power-law index changed as $N=1$, and a relatively bigger difference was shown for $N=5$. This is due to the fact that the present theoretical model is based on 3D elasticity, which can give the exact solution for this system, while the FSDT based model is capable of presenting accurate results for relatively thin plate and in low and intermediate frequency range. In addition, a shear force correction factor is required in FSDT to take in account the nonuniformity of the shear strain distribution through the thickness of the panel. A constant shear correction factor was used in Chandra et al. [22], which is usually reasonable for isotropic homogeneous plates and therefor a good agreement is achieved for $N=0$ due to the fact that FGM plate with power-law index $N=0$ is representative of monoceramic, that is, isotropic, alumina plate. However, the constant shear correction factor is not appropriate for FGM plates due to the material properties and geometric dimension of FGM plates [24, 25], which results in some discrepancy between the two predictions for FGM with power-law index of $N=1$ and $N=5$. In order to 
TABLE 1: Structural modes corresponding to the peaks in Figure 6: comparison between the present work and Chandra et al. [22].

\begin{tabular}{|c|c|c|c|c|c|}
\hline \multirow{2}{*}{$\begin{array}{l}\text { Peaks } \\
\text { number }\end{array}$} & \multirow{2}{*}{$\begin{array}{l}\text { Mode } \\
\text { number } \\
(m, n)\end{array}$} & \multirow{2}{*}{ Method } & \multicolumn{3}{|c|}{ Power-law index $N$} \\
\hline & & & 0 & 1 & 5 \\
\hline \multirow{2}{*}{1} & \multirow{2}{*}{$1(1,1)$} & Present work & 146.1 & 111.5 & 96.2 \\
\hline & & Chandra & 146.1 & 111.5 & 96.19 \\
\hline \multirow{2}{*}{2} & \multirow{2}{*}{$5(3,1)$} & Present work & 602.1 & 459.6 & 396.2 \\
\hline & & Chandra & 602.1 & 459.6 & 396.3 \\
\hline \multirow{2}{*}{3} & \multirow{2}{*}{$6(1,3)$} & Present work & 858.4 & 655.3 & 564.8 \\
\hline & & Chandra & 858.3 & 655.2 & 564.9 \\
\hline \multirow{2}{*}{4} & \multirow{2}{*}{$11(3,3)$} & Present work & 1313.6 & 1002.9 & 864.3 \\
\hline & & Chandra & 1313.5 & 1002.8 & 864.5 \\
\hline \multirow{2}{*}{5} & \multirow{2}{*}{$13(5,1)$} & Present work & 1512.6 & 1154.8 & 995.1 \\
\hline & & Chandra & 1512.5 & 1154.7 & 995.4 \\
\hline \multirow{2}{*}{6} & \multirow{2}{*}{$19(5,3)$} & Present work & - & 1697.1 & 1462.0 \\
\hline & & Chandra & - & 1696.9 & 1462.6 \\
\hline \multirow{2}{*}{7} & \multirow{2}{*}{$20(1,5)$} & Present work & - & 1740.5 & 1499.3 \\
\hline & & Chandra & - & 1740.2 & 1499.9 \\
\hline \multirow{2}{*}{8} & \multirow{2}{*}{$24(3,5)$} & Present work & - & - & 1797.3 \\
\hline & & Chandra & - & - & 1798.4 \\
\hline \multirow{2}{*}{9} & \multirow{2}{*}{$27(7,1)$} & Present work & - & - & 1890.4 \\
\hline & & Chandra & - & - & 1891.6 \\
\hline
\end{tabular}

illustrate this point clearly, a relatively thicker FGM plate ( $h=0.03 \mathrm{~m}$ ) is considered, and the comparison of the first ten structural frequencies is shown in Table 2. The result of Chandra can be obtained following the method in references $[22,23]$. It can be found that a relatively bigger discrepancy exists compared with the result for FGM of thickness $h=$ $0.003 \mathrm{~m}$, and a similar result is noted that the discrepancy of the two predictions for $N=5$ is bigger than that for $N=0$ and $N=1$.

The aforementioned detail demonstrates the advantage of the present $3 \mathrm{D}$ elasticity based model and the necessity for the application of the present model in sound radiation of FGM plates where high accuracy is required.

3.2. Sound Radiation Characteristics of FGM Plates. To investigate further sound radiation characteristics of FGM plates, several parametric studies are conducted in the previous subsection. FGM plate composed of zirconia $\left(\mathrm{ZrO}_{2}\right)$ at the top surface and aluminum (Al) at the bottom surface with power-law distribution of properties through the thickness with respect to volume fraction is considered. The material properties of the constituent are $[22,23,28]$, for zirconia, $E_{c}=200 \mathrm{GPa}, \rho_{c}=5700 \mathrm{~kg} / \mathrm{m}^{3}$, and $v_{c}=0.3$, while, for aluminum, they are $E_{m}=70 \mathrm{GPa}, \rho_{m}=2700 \mathrm{~kg} / \mathrm{m}^{3}$, and $v_{m}=0.3$. The plate is assumed to be simply supported on all edges and placed in an infinite baffle. The air density is taken as $\rho_{0}=1.21 \mathrm{~kg} / \mathrm{m}^{3}$, and the sound speed in the air is $c_{0}=343 \mathrm{~m} / \mathrm{s}$ [22]. The dimensional size of the plate is $0.4 \mathrm{~m} \times$ $0.3 \mathrm{~m} \times 0.01 \mathrm{~m}$ and a damping loss factor of 0.01 is taken for all the following calculations except for specially noted cases. In
TABLE 2: The first 10 structural frequencies of the FGM plate with thickness $h=0.03 \mathrm{~m}$ : comparison between the present work and Chandra et al. [22].

\begin{tabular}{|c|c|c|c|c|}
\hline \multirow{2}{*}{ Mode number $(m, n)$} & \multirow{2}{*}{ Method } & \multicolumn{3}{|c|}{ Power-law index $N$} \\
\hline & & 0 & 1 & 5 \\
\hline \multirow{2}{*}{$1(1,1)$} & Present work & 1438.8 & 1100.2 & 943.0 \\
\hline & Chandra & 1437.9 & 1099.4 & 945.3 \\
\hline \multirow{2}{*}{$2(2,1)$} & Present work & 3068.5 & 2350.9 & 2002.9 \\
\hline & Chandra & 3064.4 & 2347.3 & 2012.1 \\
\hline \multirow{2}{*}{$3(1,2)$} & Present work & 3961.2 & 3037.9 & 2580.0 \\
\hline & Chandra & 3954.5 & 3032.0 & 2594.8 \\
\hline \multirow{2}{*}{$4(2,2)$} & Present work & 5508.9 & 4232.2 & 3575.9 \\
\hline & Chandra & 5496.2 & 4220.9 & 3602.5 \\
\hline \multirow{2}{*}{$5(3,1)$} & Present work & 5667.3 & 4354.7 & 3677.5 \\
\hline & Chandra & 5654.0 & 4342.7 & 3705.5 \\
\hline \multirow{2}{*}{$6(1,3)$} & Present work & 7895.6 & 6081.4 & 5099.7 \\
\hline & Chandra & 7870.2 & 6058.4 & 5150.8 \\
\hline \multirow{2}{*}{$7(3,2)$} & Present work & 7986.3 & 6151.9 & 5157.4 \\
\hline & Chandra & 7960.4 & 6128.4 & 5209.6 \\
\hline \multirow{2}{*}{$8(4,1)$} & Present work & 9092.9 & 7012.4 & 5859.6 \\
\hline & Chandra & 9059.7 & 6982.1 & 5925.2 \\
\hline \multirow{2}{*}{$9(2,3)$} & Present work & 9329.1 & 7196.3 & 6009.1 \\
\hline & Chandra & 9294.3 & 7164.4 & 6077.7 \\
\hline \multirow{2}{*}{$10(4,2)$} & Present work & 11267.3 & 8708.2 & 7232.4 \\
\hline & Chandra & 11217.4 & 8662.2 & 7327.6 \\
\hline
\end{tabular}

addition, to excite a relatively large number of modes, a unit point excitation force is applied at $(x=0.1 \mathrm{~m}, y=0.1 \mathrm{~m})$ relative to the lower left corner and the frequency is varied.

3.2.1. Investigation into the Effect of Power-Law Index $N$. Figure 7 shows the effects of material distribution on the sound radiation of FGM plates. Three types of power-law index are considered, that is, $N=0.2, N=1$, and $N=5$, which are representatives of FGM plates that are ceramic rich, linear, and metal rich, respectively. It can be seen that the sound radiation power of functionally graded plates is influenced significantly by the volume fraction distributions of the constituents, especially at high frequency range.

As presented in (4), the power-law index has an influence on the material properties distribution, including density, Young's modulus, and Poisson's ratio simultaneously. In order to have a more accurate survey on sound radiation of FGM plates, the effects of each of graded elasticity modulus, density, and Poisson's ratio through the thickness on sound radiation of FGM plates are investigated.

Figure 8 presents the effect of graded elasticity modulus on sound radiation of FGM plates. Sound radiation from assumed FGM plates of which material properties are the same as aluminum except for Young's modulus is considered. Young's modulus at the top surface and bottom surface of the plate is $200 \mathrm{GPa}$ and $70 \mathrm{GPa}$, respectively, and that between the top surface and bottom surface changes gradually and continuously along the thickness direction. As is shown in the figure, the modes shift towards low frequencies with 


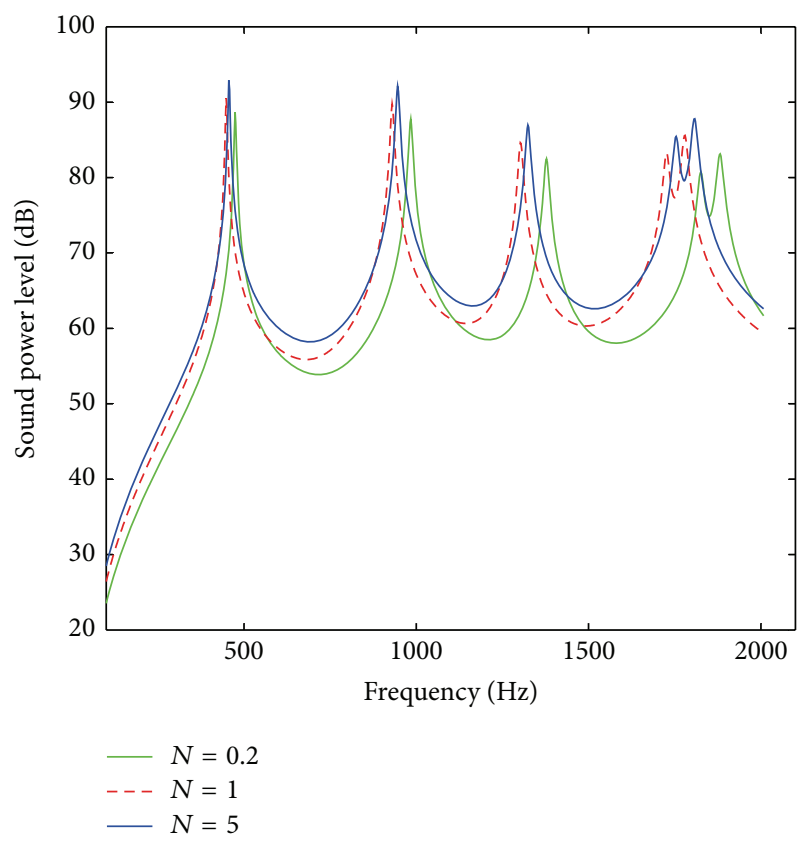

FIGURE 7: Sound radiation of FGM plates with different power-law index.

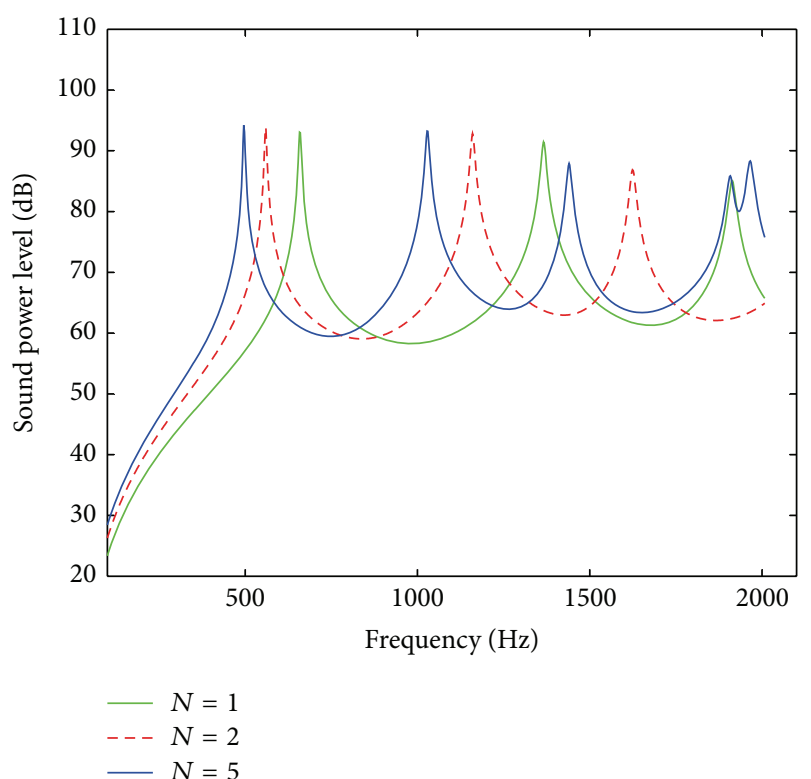

FIGURE 8: The effect of graded Young's modulus through thickness on sound radiation of FGM plates.

the increase of power-law index $N$. From (4), gradually increasing the power-law index results in a proportional reduction in modulus of elasticity. Therefore, the decrease in the rigidity of the graded material through the thickness leads to a lower modal frequency of the FGM plate.

Figure 9 illustrates the changes in sound radiation power from FGM plates with only graded densities from $5700 \mathrm{~kg} / \mathrm{m}^{3}$ at the top surface to $2700 \mathrm{~kg} / \mathrm{m}^{3}$ at the bottom surface. No considerable changes are seen in sound power level at

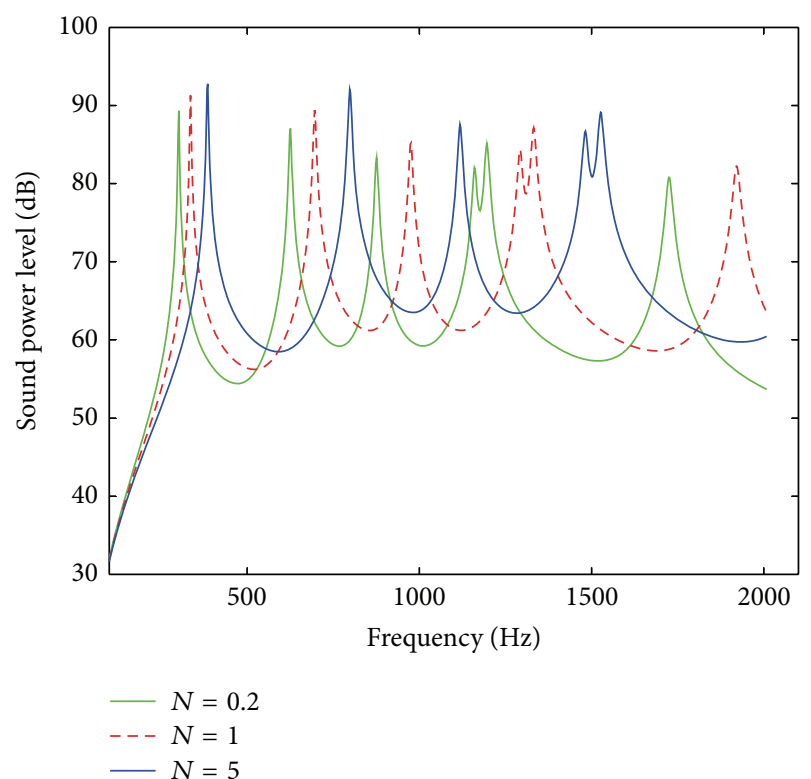

FIGURE 9: The effect of graded density through thickness on sound radiation of FGM plates.

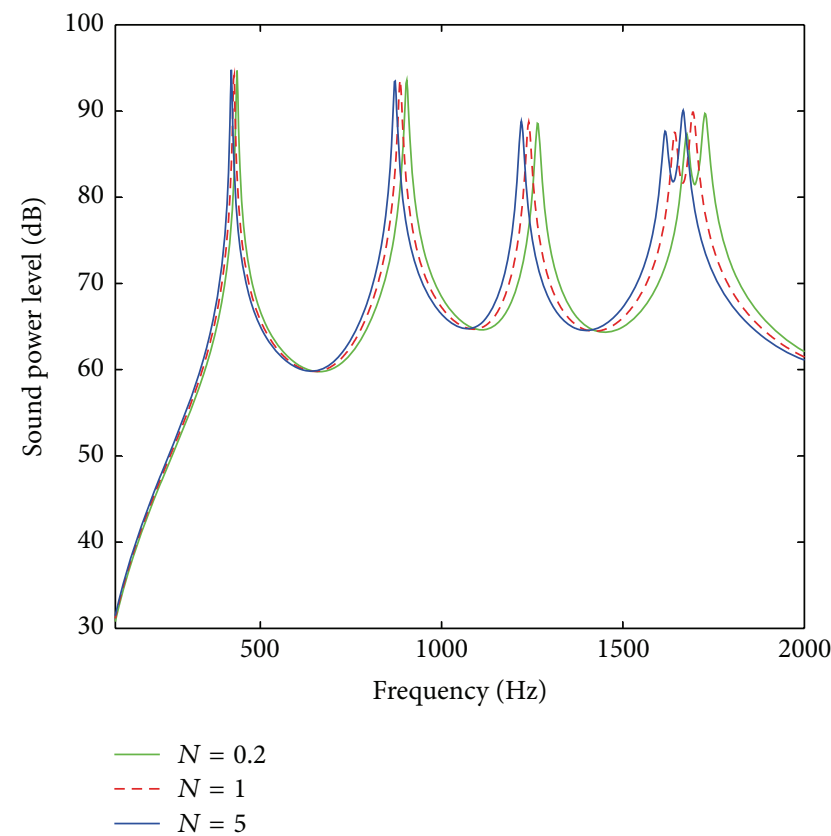

FIGURE 10: The effect of graded Poisson's ratio through thickness on sound radiation of FGM plates.

very low frequencies; however, as depicted in the figure, the increase of power-law index results in a shift of the structural frequency towards high frequency range.

Figure 10 shows the variation of sound radiation power with different power-law index of graded Poisson's ratio of the FGM plate. Poisson's ratio at the top surface and at the bottom surface is 0.4 and 0.2 , respectively, and that between the top surface and the bottom surface changes gradually with different power-law scheme through the thickness. It is 


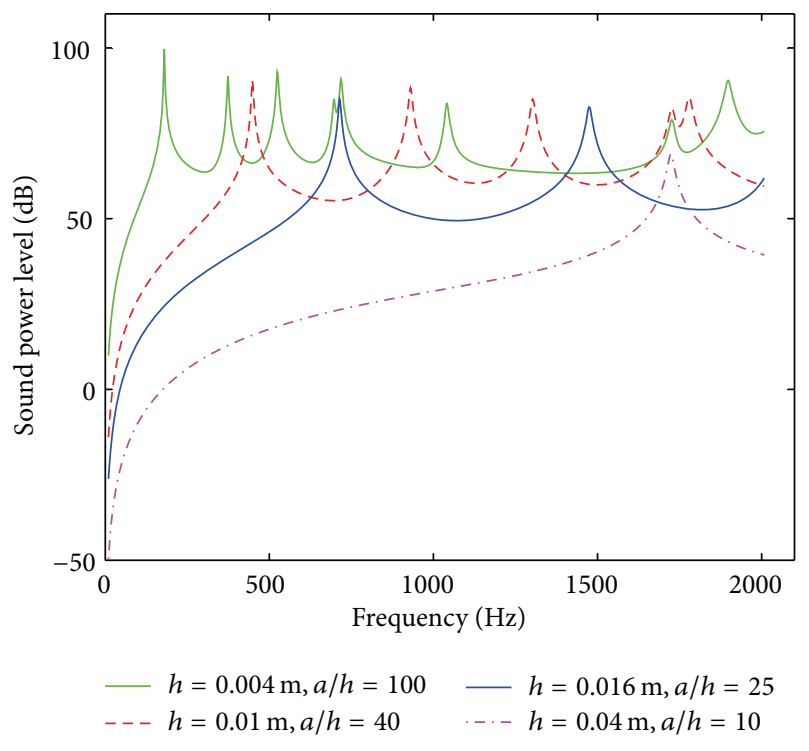

FIGURE 11: The effect of thickness on sound radiation of FGM plates.

always considered that there is no need of considering the graded effect of Poisson's ratio and Poisson's ratio is always assumed to be constant in the researches of FGM structures. As depicted in the figure, the influence of graded Poisson's ratio on sound radiation of FGM plate is small compared with that of the graded elasticity modulus and the graded density. However, the effect of graded Poisson's ratio on sound radiation of FGM plate must not be overlooked, especially at high frequencies when Poisson's ratio of the constituent materials is very distinct. Some similar conclusions are also drawn for the bending and vibration of functionally graded microbeams; see [48].

3.2.2. Investigation into the Effect of the Plate Geometry. Figure 11 shows the variation of sound radiation power with different thickness of the FGM plate. FGM plates with constant length and width $(a=0.4 \mathrm{~m}, b=0.3 \mathrm{~m})$ but different thickness, that is, $h=0.004 \mathrm{~m}, h=0.01 \mathrm{~m}, h=0.016 \mathrm{~m}$, and $h=0.04 \mathrm{~m}$, are considered, and the power-law index is taken as $N=1$. The plot shows that the thickness is an important geometrical parameter for the acoustic properties of the plate. With an increase of thickness, the first mode of the plate shifts towards high frequencies, and fewer peaks occur in the frequency range showed. In addition, the increase of the thickness of FGM plate leads to a reduction of sound radiation.

Aspect ratio is another parameter of the plate. In order to investigate the effect of aspect ratio on the sound radiation of FGM plate, plate with distinct three aspect ratio sizes (i.e., $0.4 \mathrm{~m} \times 0.3 \mathrm{~m}, 0.4 \mathrm{~m} \times 0.4 \mathrm{~m}$, and $0.4 \mathrm{~m} \times 0.5 \mathrm{~m}$ ) is considered and the results are presented in Figure 12. It is observed that the aspect ratio has a significant effect on sound radiation of the FGM plate.

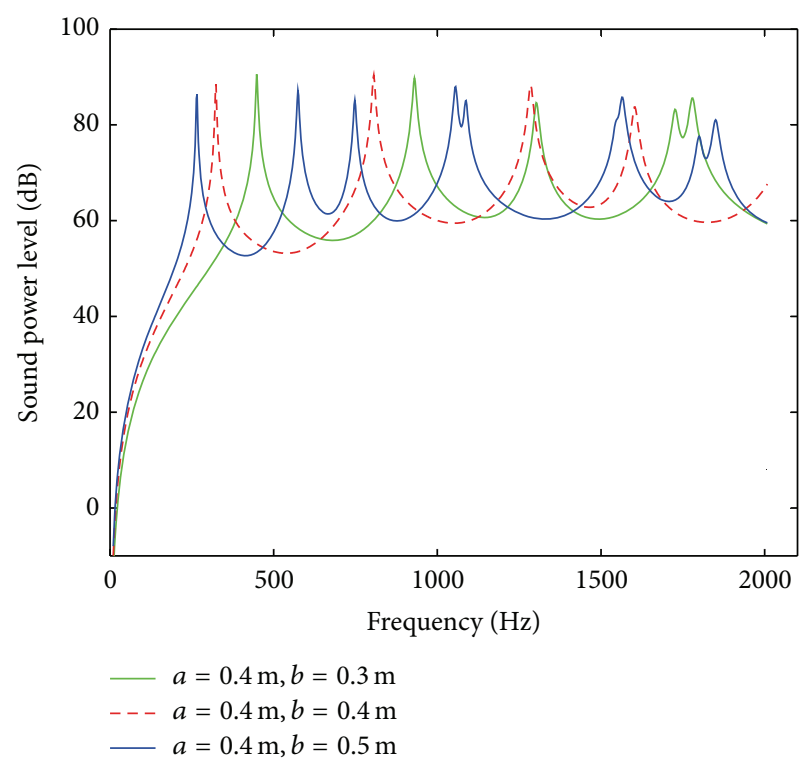

FIgURE 12: The effect of aspect ratio on sound radiation of FGM plates.

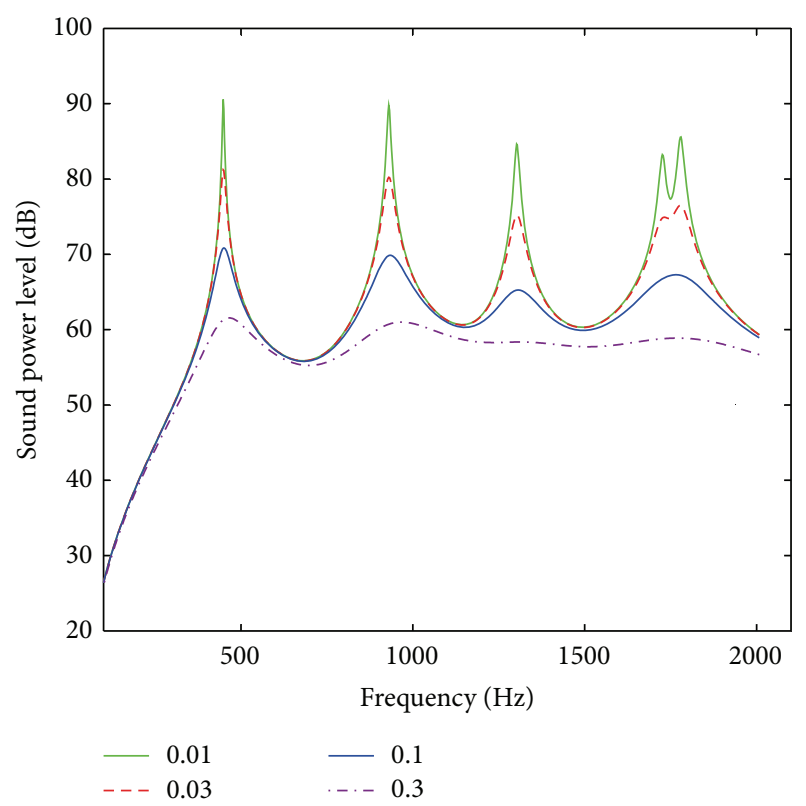

FIGURE 13: The effect of damping loss factor on sound radiation of FGM plates.

3.2.3. Investigation into the Effect of Damping. The result in Figure 13 shows the effects of damping loss factor on sound radiation of FGM plate. As depicted in the figure, the sound radiation power is independent of the damping loss factor at frequencies below the first mode. The damping loss factor leads to the reduction of the peaks and no considerable change of the sound power level is seen at other frequencies when the damping loss factor is relatively small. However, when the damping loss factor is relatively large, for example, 0.3 , the sound power level seems to be 


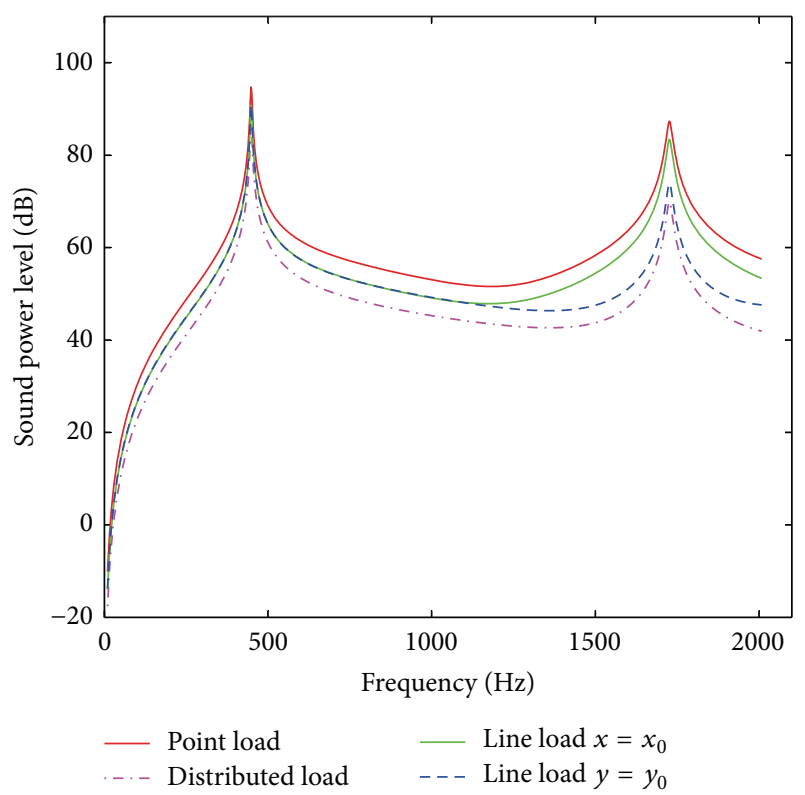

FIGURE 14: The effect of load type on sound radiation of FGM plates.

independent of frequency. The loss factor is a function of frequency in practical applications and, in general, low values of damping are measured at high frequencies [46]. Therefore, it is essential to determine the damping loss factor of the FGM plate experimentally.

3.2.4. Investigation into the Effect of Load Type. The above observations are determined by the fact that the FGM plate is excited by a concentrated load or a point load; however, the FGM structures are subjected to different types of load in practical applications. In order to investigate the effect of force type on the sound radiation of FGM plate, three types of forces, that is, concentrated load, line load, and distributed load, are considered and the results are shown in Figure 14. The concentrated load is a $1 \mathrm{~N}$ force applied at the center of the plate, the line load is $10 / 3 \mathrm{~N} / \mathrm{m}$ applied at $x=0.2 \mathrm{~m}$ of the plate or $2.5 \mathrm{~N} / \mathrm{m}$ applied at $y=0.15 \mathrm{~m}$ of the plate, and the distributed load is $25 / 3 \mathrm{~N} / \mathrm{m}^{2}$. It should be noted that the three types of load share an equal total load acting on the plate. Only two peaks exist in the frequency range, which is due to the fact that all the modes with combination of even numbers are not well excited and only the odd-odd combination of modes (1-1, 3-1) appears. The result in the figure reveals that the force type has no effects on the frequencies where peaks appear; however, the force type has a significant effect on the sound power level. The FGM plate under the excitation of point load can radiate much larger sound power compared with the other two types of load. For example, a difference of about $10 \mathrm{~dB}$ is achieved between the point load and the distributed load from $500 \mathrm{~Hz}$ to $1000 \mathrm{~Hz}$, and about $20 \mathrm{~dB}$ can be found around $1500 \mathrm{~Hz}$. In addition, it can be found that sound radiation of the plate excited by the line load $x=x_{0}$ and line load $y=y_{0}$ shows no considerable difference from $1 \mathrm{~Hz}$ to about $1000 \mathrm{~Hz}$ and a difference of about $6 \mathrm{~dB}$ from $1500 \mathrm{~Hz}$ to $2000 \mathrm{~Hz}$.

\section{Conclusions}

In the present paper, an analytical method for sound radiation of FGM plate based on 3D elasticity has been developed. The state space method is utilized to derive the structural model of the plate and sound radiation of the vibration plate is calculated by employing the Rayleigh integral approach. The accuracy of the present approach is validated by comparing the numerical results of sound radiation from homogeneous plates and FGM plates with those available in the literature and good agreements are achieved. Moreover, detailed comparison of the present model with FSDT based model demonstrates the advantage and necessity for the application of the 3D elasticity based model for sound radiation of FGM plates where high accuracy is required. Finally, several parametric studies on the effects of material distribution, plate geometry, damping, and force type on sound radiation of FGM plates are carried out. It is found that FGM plates have similar characteristics of sound radiation with homogeneous plates. In addition, it is found that the effect of graded Poisson's ratio on sound radiation of FGM plate must not be overlooked, especially at high frequencies when Poisson's ratio of the constituent materials is very distinct.

Several practical applications are related to these analytical formulations developed in this study such as vibroacoustic sensitivity analysis, the material phase distribution identification, and parameter optimization.

\section{Conflict of Interests}

The authors declare that there is no conflict of interests regarding the publication of this paper.

\section{Acknowledgments}

This research was supported by the National Natural Science Foundation of China (no. 51175195 and no. 11204098). The authors appreciate the advice of Professor Jianguo Wang (Hefei University of Technology, China) and Dr. N. Chandra (CSIR-National Aerospace Laboratories, India).

\section{References}

[1] H. T. Thai and S. E. Kim, "A review of theories for the modeling and analysis of functionally graded plates and shells," Composite Structures, vol. 128, pp. 70-86, 2015.

[2] K. Swaminathan, D. T. Naveenkumar, A. M. Zenkour, and E. Carrera, "Stress, vibration and buckling analyses of FGM plates-a state-of-the-art review," Composite Structures, vol. 120, pp. 10-31, 2015.

[3] D. K. Jha, T. Kant, and R. K. Singh, "A critical review of recent research on functionally graded plates," Composite Structures, vol. 96, pp. 833-849, 2013.

[4] W. Q. Chen, H. M. Wang, and R. H. Bao, "On calculating dispersion curves of waves in a functionally graded elastic plate," Composite Structures, vol. 81, no. 2, pp. 233-242, 2007.

[5] P. Jeyaraj, N. Ganesan, and C. Padmanabhan, "Vibration and acoustic response of a composite plate with inherent material 
damping in a thermal environment," Journal of Sound and Vibration, vol. 320, no. 1-2, pp. 322-338, 2009.

[6] Z. S. Xu, Q. B. Huang, and Z. G. Zhao, "Topology optimization of composite material plate with respect to sound radiation," Engineering Analysis with Boundary Elements, vol. 35, no. 1, pp. 61-67, 2011.

[7] S. Li and Q. Huang, "A fast multipole boundary element method based on the improved Burton-Miller formulation for three-dimensional acoustic problems," Engineering Analysis with Boundary Elements, vol. 35, no. 5, pp. 719-728, 2011.

[8] M. Villot, C. Guigou, and L. Gagliardini, "Predicting the acoustical radiation of finite size multi-layered structures by applying spatial windowing on infinite structures," Journal of Sound and Vibration, vol. 245, no. 3, pp. 433-455, 2001.

[9] E. G. Williams, "Numerical evaluation of the radiation from unbaffled, finite plates using the FFT," The Journal of the Acoustical Society of America, vol. 74, no. 1, pp. 343-347, 1983.

[10] C. H. Oppenheimer and S. Dubowsky, "A radiation efficiency for unbaffled plates with experimental validation," Journal of Sound and Vibration, vol. 199, no. 3, pp. 473-489, 1997.

[11] Y. Qiao and Q. Huang, "The sound radiation characteristic from Un-baffled rectangular plates," International Journal of Mechanics and Materials in Design, vol. 2, no. 3-4, pp. 245-258, 2005.

[12] A. Putra and D. J. Thompson, "Sound radiation from rectangular baffled and unbaffled plates," Applied Acoustics, vol. 71, no. 12, pp. 1113-1125, 2010.

[13] A. Putra and D. J. Thompson, "Radiation efficiency of unbaffled and perforated plates near a rigid reflecting surface," Journal of Sound and Vibration, vol. 330, no. 22, pp. 5443-5459, 2011.

[14] G. Squicciarini, D. J. Thompson, and R. Corradi, “The effect of different combinations of boundary conditions on the average radiation efficiency of rectangular plates," Journal of Sound and Vibration, vol. 333, no. 17, pp. 3931-3948, 2014.

[15] X. F. Zhang and W. L. Li, "A unified approach for predicting sound radiation from baffled rectangular plates with arbitrary boundary conditions," Journal of Sound and Vibration, vol. 329, no. 25, pp. 5307-5320, 2010.

[16] Q. Geng and Y. M. Li, "Analysis of dynamic and acoustic radiation characters for a flat plate under thermal environments," International Journal of Applied Mechanics, vol. 4, no. 3, Article ID 1250028, 2012.

[17] E. Reissner, "The effect of transverse shear deformation on the bending of elastic plates," Journal of Applied Mechanics, vol. 12, pp. 69-77, 1945.

[18] R. D. Mindlin, "Influence of rotary inertia and shear on flexural motions of isotropic elastic plates," Journal of Applied Mechanics, vol. 18, no. 1, pp. 31-38, 1951.

[19] S. H. Hashemi, K. Khorshidi, and H. R. D. Taher, "Exact acoustical analysis of vibrating rectangular plates with two opposite edges simply supported via Mindlin plate theory," Journal of Sound and Vibration, vol. 322, no. 4-5, pp. 883-900, 2009.

[20] X. Cao, H. Hua, and Z. Zhang, "Sound radiation from shear deformable stiffened laminated plates," Journal of Sound and Vibration, vol. 330, no. 16, pp. 4047-4063, 2011.

[21] X. W. Yin, X. J. Gu, H. F. Cui, and R. Y. Shen, "Acoustic radiation from a laminated composite plate reinforced by doubly periodic parallel stiffeners," Journal of Sound and Vibration, vol. 306, no. 3-5, pp. 877-889, 2007.
[22] N. Chandra, S. Raja, and K. V. N. Gopal, "Vibro-acoustic response and sound transmission loss analysis of functionally graded plates," Journal of Sound and Vibration, vol. 333, no. 22, pp. 5786-5802, 2014.

[23] H.-T. Thai and D.-H. Choi, "A simple first-order shear deformation theory for the bending and free vibration analysis of functionally graded plates," Composite Structures, vol. 101, pp. 332-340, 2013.

[24] T.-K. Nguyen, K. Sab, and G. Bonnet, "First-order shear deformation plate models for functionally graded materials," Composite Structures, vol. 83, no. 1, pp. 25-36, 2008.

[25] T.-K. Nguyen, K. Sab, and G. Bonnet, "Shear correction factors for functionally graded plates," Mechanics of Advanced Materials and Structures, vol. 14, no. 8, pp. 567-575, 2007.

[26] J. N. Reddy, "Analysis of functionally graded plates," International Journal for Numerical Methods in Engineering, vol. 47, no. 1-3, pp. 663-684, 2000.

[27] J. Reddy, "A general nonlinear third-order theory of functionally graded plates," International Journal of Aerospace and Lightweight Structures, vol. 1, pp. 1-21, 2011.

[28] K. Daneshjou, M. M. Shokrieh, M. G. Moghaddam, and R. Talebitooti, "Analytical model of sound transmission through relatively thick FGM cylindrical shells considering third order shear deformation theory," Composite Structures, vol. 93, no. 1, pp. 67-78, 2010.

[29] Y. F. Hwang, M. Kim, and P. J. Zoccola, "Acoustic radiation by point- or line-excited laminated plates," Journal of Vibration and Acoustics, vol. 122, no. 3, pp. 189-195, 2000.

[30] C. Shen, F. X. Xin, and T. J. Lu, "A 3-D elasticity theory based model for acoustic radiation from multilayered anisotropic plates," The Journal of the Acoustical Society of America, vol. 135, no. 5, pp. EL232-EL238, 2014.

[31] S. M. Hasheminejad and H. Keshavarzpour, "Active sound radiation control of a thick piezolaminated smart rectangular plate," Journal of Sound and Vibration, vol. 332, no. 20, pp. 47984816, 2013.

[32] C. Huang and S. Nutt, "An analytical study of sound transmission through unbounded panels of functionally gradedmaterials," Journal of Sound and Vibration, vol. 330, no. 6, pp. 11531165, 2011.

[33] Z. Zhong and E. T. Shang, "Three-dimensional exact analysis of a simply supported functionally gradient piezoelectric plate," International Journal of Solids and Structures, vol. 40, no. 20, pp. 5335-5352, 2003.

[34] W. Q. Chen and K. Y. Lee, "Alternative state space formulations for magnetoelectric thermoelasticity with transverse isotropy and the application to bending analysis of nonhomogeneous plates," International Journal of Solids and Structures, vol. 40, no. 21, pp. 5689-5705, 2003.

[35] J. Wang, L. Qu, and F. Qian, "State vector approach of freevibration analysis of magneto-electro-elastic hybrid laminated plates," Composite Structures, vol. 92, no. 6, pp. 1318-1324, 2010.

[36] A. L. Shuvalov, "A sextic formalism for three-dimensional elastodynamics of cylindrically anisotropic radially inhomogeneous materials," Proceedings of the Royal Society A: Mathematical, Physical and Engineering Scienc, vol. 459, no. 2035, pp. 16111639, 2003.

[37] C. Baron, "Propagation of elastic waves in an anisotropic functionally graded hollow cylinder in vacuum," Ultrasonics, vol. 51, no. 2, pp. 123-130, 2011. 
[38] A. N. Norris, A. J. Nagy, and F. A. Amirkulova, "Stable methods to solve the impedance matrix for radially inhomogeneous cylindrically anisotropic structures," Journal of Sound and Vibration, vol. 332, no. 10, pp. 2520-2531, 2013.

[39] S. Li and X. H. Li, "The effects of distributed masses on acoustic radiation behavior of plates," Applied Acoustics, vol. 69, no. 3, pp. 272-279, 2008.

[40] A. Geslain, J. P. Groby, O. Dazel, S. Mahasaranon, K. V. Horoshenkov, and A. Khan, "An application of the Peano series expansion to predict sound propagation in materials with continuous pore stratification," Journal of the Acoustical Society of America, vol. 132, no. 1, pp. 208-215, 2012.

[41] W. Q. Chen, Z. G. Bian, and H. J. Ding, “Three-dimensional vibration analysis of fluid-filled orthotropic FGM cylindrical shells," International Journal of Mechanical Sciences, vol. 46, no. 1, pp. 159-171, 2004.

[42] S. M. Hasheminejad and M. Rajabi, "Acoustic scattering characteristics of a thick-walled orthotropic cylindrical shell at oblique incidence," Ultrasonics, vol. 47, no. 1-4, pp. 32-48, 2007.

[43] J. Zhu, W. Q. Chen, G. R. Ye, and J. Z. Fu, "Waves in fluid-filled functionally graded piezoelectric hollow cylinders: a restudy based on the reverberation-ray matrix formulation," Wave Motion, vol. 50, no. 3, pp. 415-427, 2013.

[44] B. Woodward and M. Kashtalyan, "3D elasticity analysis of sandwich panels with graded core under distributed and concentrated loadings," International Journal of Mechanical Sciences, vol. 53, no. 10, pp. 872-885, 2011.

[45] L. Cremer, M. Heckl, and B. A. Petersson, Structure-Borne Sound: Structural Vibrations and Sound Radiation at Audio Frequencies, Springer Science \& Business Media, 2005.

[46] J. P. Arenas, "Matrix method for estimating the sound power radiated from a vibrating plate for noise control engineering applications," Latin American Applied Research, vol. 39, no. 4, pp. 345-352, 2009.

[47] A. P. Berkhoff, "Sensor scheme design for active structural acoustic control," The Journal of the Acoustical Society of America, vol. 108, no. 3, pp. 1037-1045, 2000.

[48] M. Şimşek and J. N. Reddy, "Bending and vibration of functionally graded microbeams using a new higher order beam theory and the modified couple stress theory," International Journal of Engineering Science, vol. 64, pp. 37-53, 2013. 


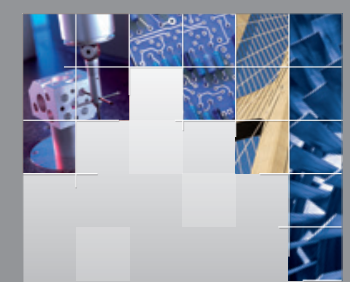

\section{Enfincering}
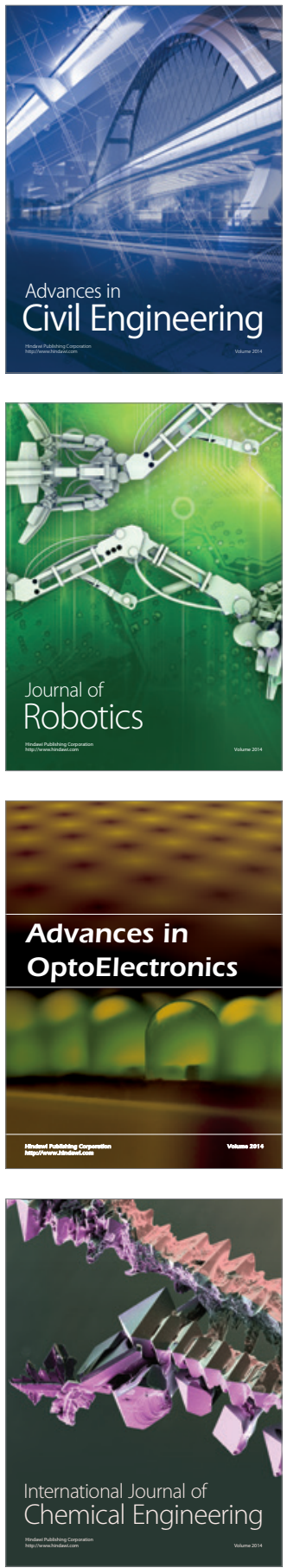

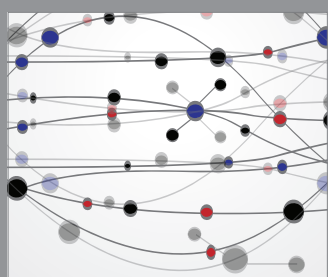

The Scientific World Journal

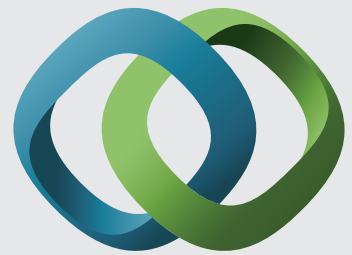

\section{Hindawi}

Submit your manuscripts at

http://www.hindawi.com
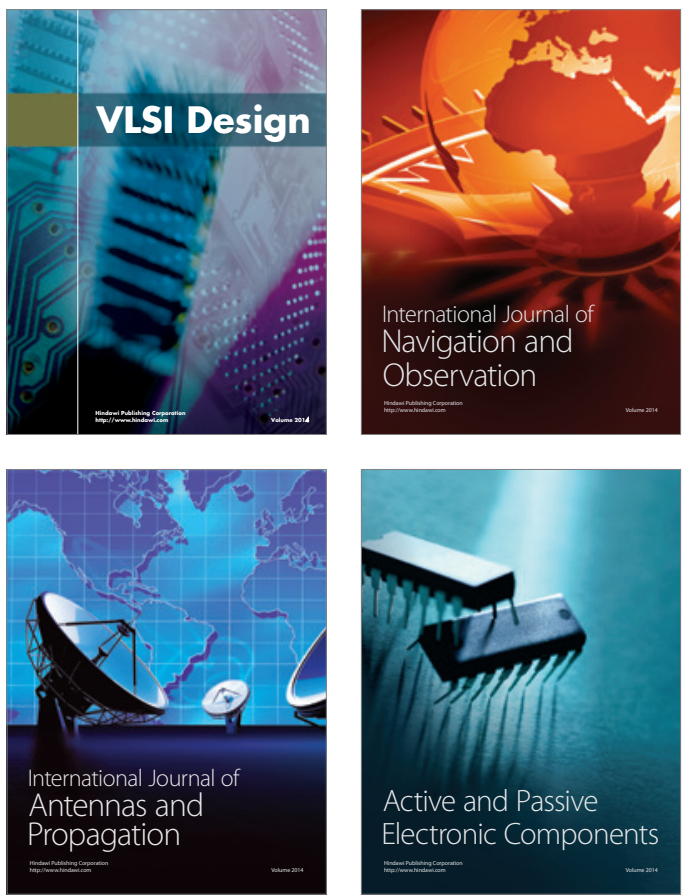
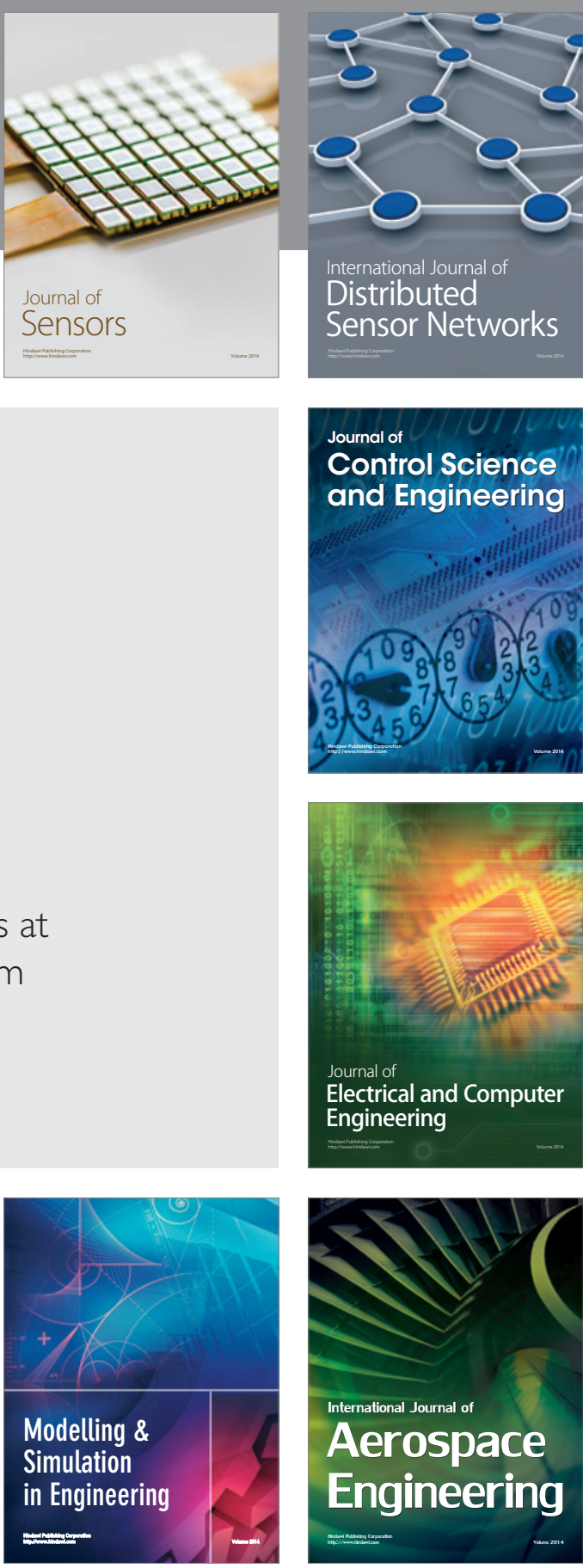

International Journal of

Distributed

Sensor Networks

Journal of

Control Science

and Engineering
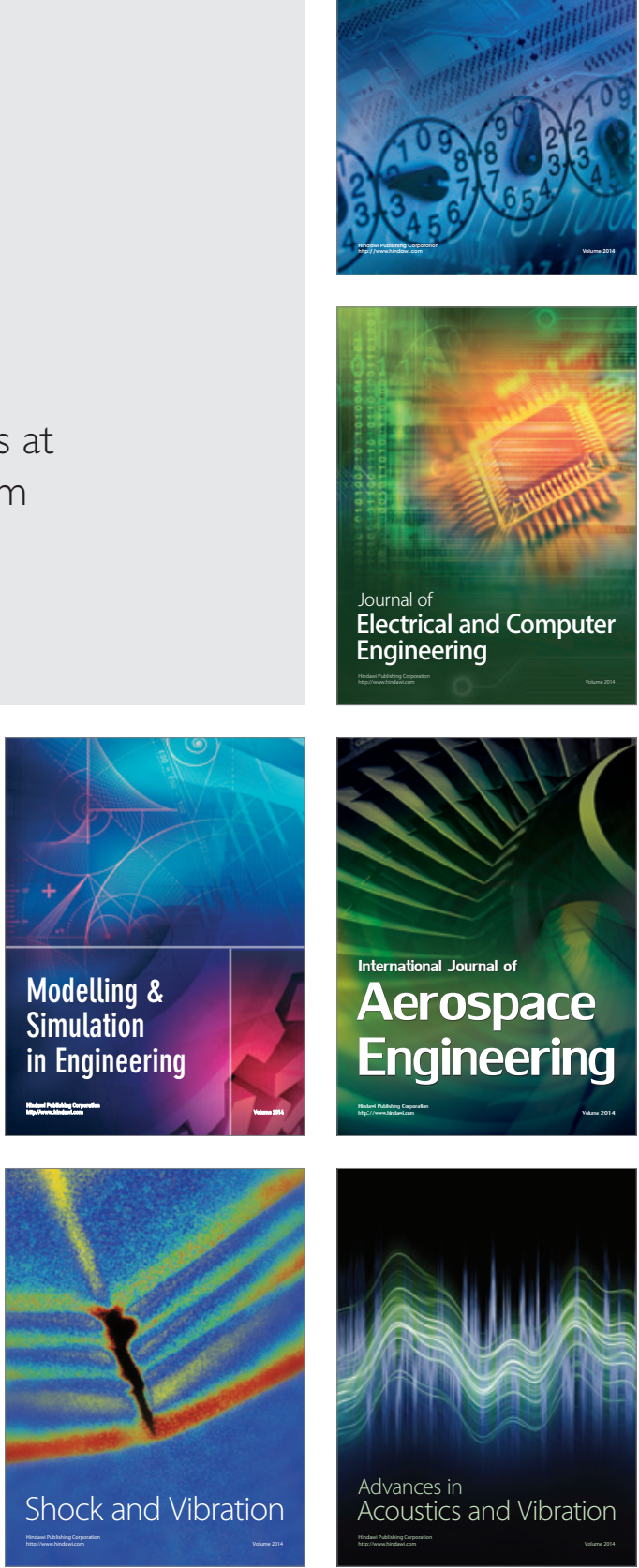